\title{
Experimental and modelling studies of the transient tribological behaviour of a two-phase lubricant under complex loading conditions
}

\author{
Xiao YANG ${ }^{1}$, Lemeng ZHANG ${ }^{1}$, Denis J. POLITIS ${ }^{2}$, Jie ZHANG ${ }^{1}$, Mohammad M. GHARBI ${ }^{3}$, David LEYVRAZ ${ }^{4}$, \\ Liliang WANG ${ }^{1, *}$ \\ ${ }^{1}$ Department of Mechanical Engineering, Imperial College London, London SW7 2AZ, UK \\ ${ }^{2}$ Department of Mechanical and Manufacturing Engineering, University of Cyprus, Nicosia 1678, Cyprus \\ ${ }^{3}$ Houghton Deutschland GmbH, Giselherstraße 57, Dortmund 44319, Germany \\ ${ }^{4}$ Novelis Switzerland SA, Novelis Innovation Center Sierre, Sierre CH-3960, Switzerland \\ Received: 06 April 2021 / Revised: 21 June 2021 / Accepted: 19 July 2021 \\ (C) The author(s) 2021.
}

\begin{abstract}
The transient tribological phenomenon and premature lubricant breakdown have been widely observed in metal forming, leading to excessive friction at the contact interfaces. In this research, the transient tribological behaviour of a two-phase lubricant were studied under complex loading conditions, featuring abrupt interfacial temperature, contact load, and sliding speed changes, thus representing the severe interfacial conditions observed in warm/hot metal forming applications. The strong experimental evidence indicates that the evolution of friction was attributed to the physical diminution and chemical decomposition effects. As such, a visco-mechanochemical interactive friction model was developed to accurately predict the transient tribological behaviour of the two-phase lubricant under complex loading conditions. The new friction model exhibited close agreements between the modelling and experimental results.
\end{abstract}

Keywords: visco-mechanochemical interactive friction model; complex loading conditions; transient tribological behaviours; two-phase lubricant

\section{Introduction}

The The transient tribological phenomenon is widely observed in a variety of scenarios such as changing lubrication mechanisms [1], third-body effects [2, 3], and varying contact conditions [4]. In metal forming processes, the contact conditions at the tool/workpiece interfaces vary historically and spatially [5-7], leading to complex loading conditions featuring abrupt temperature, load, and speed changes, which could affect the viscosity and mechanochemical behaviour of lubricants. This may lead to premature lubricant breakdown, thus resulting in poor surface quality of the formed components and reduced tool life [8-13].
Experimental work was conducted to investigate the transient tribological behaviours of an engine lubricant with Zinc dialkyldithiophosphate (ZDDP) additives. Strong experimental evidence indicated that the changing lubrication mechanisms induced by the mechanochemical characteristics of zinc/iron phosphate tribofilms influenced the transient tribological behaviour [1]. It was also found that the transient friction value as a function of the tribofilm thickness in the elastohydrodynamic lubrication condition was influenced by macroscopic shear stress rather than hydrostatic pressure. At elevated temperatures, the transient lubricant behaviours were more pronounced. In the friction tests at the interfacial temperature of up

* Corresponding author: Liliang WANG, E-mail: liliang.wang@imperial.ac.uk 
to $230{ }^{\circ} \mathrm{C}$, premature lubricant breakdown occurred, and the transient friction values were affected by lubricant properties and interfacial temperature which resulted in different peak forming forces [11].

The third body particle induced transient tribological behaviours were observed in previous works for dry sliding conditions. It was found that the evolution of friction values and galling area is attributed to the dynamic balance of entrapped wear particles and dependent on the contact load [2]. The transient coefficient of friction (COF) value under dry sliding conditions increased with interfacial temperature (over $150{ }^{\circ} \mathrm{C}$ ) and the primary friction mechanisms transformed from abrasive to adhesive wear [14]. In addition, the transient characteristics of friction were investigated between coated contact pairs, and was found to be determined by the instantaneous coating thickness [3, 15].

The complex loading induced transient characteristics of a single-phase liquid lubricant were investigated at elevated temperatures in the literature. It was found that the lubricant thickness diminution effects resulted in the premature breakdown and subsequent increase in friction values $[4,16]$. The employment of twophase (liquid-solid) lubricants with additives, such as graphite, graphite fluoride $\left(\left(\mathrm{CF}_{x}\right)_{n}\right)$, molybdenum disulphide $\left(\mathrm{MoS}_{2}\right)$, graphene, and silica particles [17-23], have shown improved performance at elevated temperatures [14, 24, 25]. In addition to the chemical solutions, the carrying agent, application methods [26, 27], interfacial temperature [28], and initial lubricant volume [10] were found to significantly influence the performance of two-phase lubricants, which was the impetus for lubricant behaviour studies under complex loading conditions [4].

Precision modelling of the transient tribological behaviour in the tool/workpiece interface is essential for the development of reliable finite element (FE) models. The framework of interactive friction modelling has been applied to describe friction evolution at room temperature in a coated system, a lubricated contact and a dry sliding condition where adhesive wear occurs. The wear process of a TiN coating under a series of contact loads was studied, and an interactive friction model was established to describe the interactive relation between coating friction and wear as three stages corresponding to different wear mechanisms and behaviours [3]. This model was capable of accurately predicting friction evolution and coating breakdown phenomenon. Hu et al. [10] investigated the interactive relation between friction values and the lubricant film thickness, and developed an interactive friction model to describe the friction evolution as a function of the sliding distance by considering the transition of lubrication mechanisms. Friction was determined by the thickness diminution effect, which was influenced by contact pressure, sliding speed, and the initial applied lubricant volume. A mechanism-based interactive friction model was developed to represent the interaction between friction and material transfer (galling) under the dry sliding condition [2]. By modelling the dynamic feature of the volume of entrapped wear particles (third body) and the complicated procedure of reaching the dynamic equilibrium, the model successfully enabled the predictions of friction evolution and formation of transfer layer from the running-in to the steady stage. Multi-scale friction models under boundary and mixed lubrication conditions have been developed [29, 30] to characterise the tribological behaviours at the tool/workpiece interface. This advanced model was implemented into FE simulations of deep-drawing processes, demonstrating accurate predictions of forming force. Specifically, the multi-scale friction model incorporated micro-scale asperity contact analysis and macro-scale stochastic description of the rough workpiece surface by considering the effects of process conditions such as normal loading and stretching of the bulk material. Recently, the multi-scale friction model was further developed to account for the effect of surface topographies on the distribution of lubricant pressures and the effect of physical properties of coated sheets under mixed and boundary lubrication conditions [31,32]. The results from the experimental and simulation analysis exhibited close agreements in forming force (as a function of punch displacement), blank draw-in, and real area of contact. The successful implementation of these advanced multi-scale friction models into FE codes have demonstrated the importance of frictional boundary conditions and their promising potential in industrial applications.

In the present work, the high-temperature transient 
tribological behaviours of a two-phase lubricant were studied under complex loading conditions, featuring abrupt changes in interfacial temperature, load, and speed. A visco-mechanochemical interactive friction model was established to predict COF evolution and the breakdown behaviour, with close agreements being achieved between the modelling and friction testing results.

\section{Methodology}

An autonomous friction testing equipment, developed by Yang et al., was utilized to enable lubricant evaluations under complex loading conditions, enabling the reproduction of interfacial conditions in metal forming [33]. This equipment comprises of hardware components (a Universal Robot UR10, and a thermal box) as shown in Fig. 1 and a robot operating system (ROS)-implemented control unit with an autonomous friction modelling software system. The fully automated UR10 robot equipped with a precision feedback control enables accurate implementation of abrupt load and speed changes, with a load changing rate of up to $1 \mathrm{~N} / \mathrm{mm}$ and speed changing rate of up to $500 \mathrm{~mm} / \mathrm{s}^{2}$, without interrupting the friction test. A load cell linked to the end effector of the robot was attached to the pin holder to enable the precision force data collection at a sampling rate of up to $250 \mathrm{~Hz}$. The thermal box was employed to realise precision temperature control $\left( \pm 2{ }^{\circ} \mathrm{C}\right)$ and the development of thermal gradient within the testing specimen (changing rate up to $3.3^{\circ} \mathrm{C} / \mathrm{mm}$ ), which was achieved by exchangeable heating channels (for cartridge heaters) and cooling channels (for liquid nitrogen) in the specimen holder (Fig. 1). The measurement of temperature distribution along the sliding direction was achieved through six k-type thermo-couples embedded in the specimen holder. The autonomous friction modelling system enables automatic management of raw data including the in-situ force and temperature data collection from the load cell and thermo-couples with subsequent processing of raw data including automatic data filtering, data smoothening, and friction model fitting during friction testing.

In the present research, the transient tribological behaviours of a two-phase lubricant, OMEGA 35, were characterised under complex loading conditions. This lubricant was widely used in hot/warm aluminium forming processes [34], which blends graphite particles in a synthetic carrier agent, polyethylene glycol (PEG). The workpiece material, AA7075 aluminium alloy, was manufactured into $75 \mathrm{~mm} \times 150 \mathrm{~mm} \times 1.6 \mathrm{~mm}$ strips. The surface roughness of the strip specimen was $0.5 \mu \mathrm{m}$. The tool material, P20 tool steel, was manufactured into pins. The pin had a hemispherical tip of $6 \mathrm{~mm}$ diameter and a roughness of $R_{a}=0.3 \mu \mathrm{m}$ (as specified by the standards of a metal forming tool

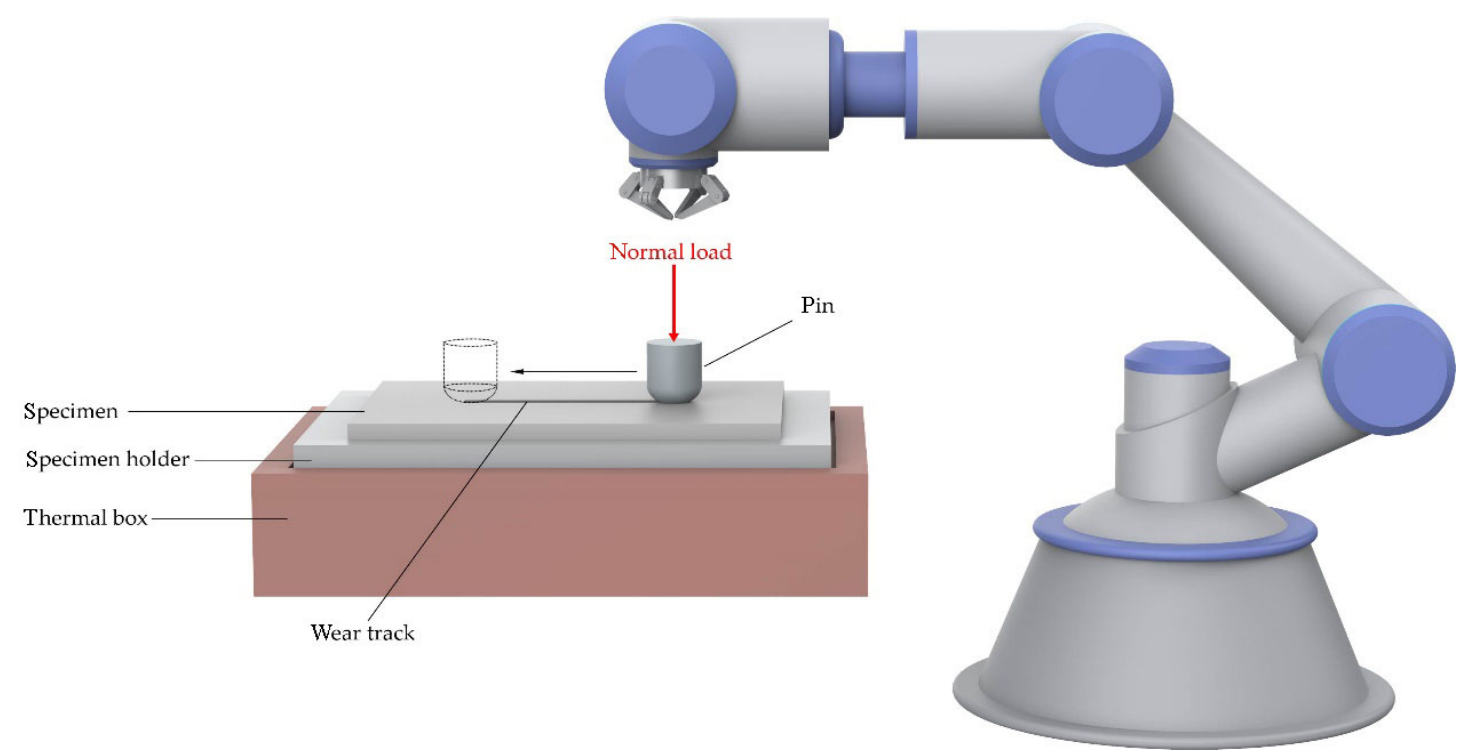

Fig. 1 Schematic diagram of the friction testing equipment, Tribo-Mate [33]. 
maker). Before the friction test was initiated, the twophase lubricant was applied with an auto-lubrication rig with the capability of applying a controlled volume of lubricant to the pin. The auto-lubrication rig achieves this by dipping the pin in pre-machined lubricant reservoirs containing a controlled volume of lubricant. The initial amount of lubricant applied was $113 \mathrm{~g} / \mathrm{m}^{2}$ for all tests in this study. The strip was subsequently heated to the target temperature and a test commenced. The test matrix utilised in the study is shown in Table 1. In the temperature changing tests, the temperature was increased from 300 to $400{ }^{\circ} \mathrm{C}$ at a rate of $1.4{ }^{\circ} \mathrm{C} / \mathrm{mm}$ and decreased from 400 to $300{ }^{\circ} \mathrm{C}$ at a rate of $-3.3^{\circ} \mathrm{C} / \mathrm{mm}$. In the load increase test, the contact load was maintained at $5 \mathrm{~N}$ before being abruptly increased to $10 \mathrm{~N}$ at a sliding distance of $20 \mathrm{~mm}$, and was subsequently maintained at $10 \mathrm{~N}$. For the load decrease test, the contact load was rapidly reduced from 10 to $5 \mathrm{~N}$ at a distance of $10 \mathrm{~mm}$. The sliding speed accelerated from 50 to $80 \mathrm{~mm} / \mathrm{s}$ at a sliding distance of $18 \mathrm{~mm}$ and decelerated from 80 to $50 \mathrm{~mm} / \mathrm{s}$ at a distance of $10 \mathrm{~mm}$ at a changing rate of up to $500 \mathrm{~mm} / \mathrm{s}^{2}$ in the speed changing tests. Three repeat tests were conducted at each testing condition. The fully automated test procedure with tribo-mate and the auto-lubrication rig successfully avoided human error; and thus ensured repeatability of the test results.

\section{Results and discussion}

\subsection{Transient lubricant behaviours of a two-phase lubricant at complex loading conditions}

Figures 2-4 demonstrate the effects of interfacial temperature (Fig. 2), contact load (Fig. 3), and sliding speed (Fig. 4), respectively, on the transient lubricant

Table 1 Friction test matrix: complex loading tests.

\begin{tabular}{cccccc}
\hline Test No. & $\begin{array}{c}\text { Interfacial } \\
\text { temperature }\left({ }^{\circ} \mathrm{C}\right)\end{array}$ & $\begin{array}{c}\text { Sliding speed } \\
(\mathrm{mm} / \mathrm{s})\end{array}$ & $\begin{array}{c}\text { Contact load } \\
(\mathrm{N})\end{array}$ & $\begin{array}{c}\text { Contact pressure } \\
(\mathrm{MPa})\end{array}$ & Note \\
\hline 1 & $300 \rightarrow 400$ & 50 & 5 & $270 \rightarrow 180$ & Temperature changing rate: 1.4 and $3.3^{\circ} \mathrm{C} / \mathrm{mm}$ \\
2 & $400 \rightarrow 300$ & 50 & 5 & $180 \rightarrow 270$ & Load changing rate: $1 \mathrm{~N} / \mathrm{mm}$ \\
3 & 300 & 50 & $5 \rightarrow 10$ & $270 \rightarrow 460$ & \\
4 & 300 & 50 & $10 \rightarrow 5$ & $460 \rightarrow 270$ & Speed changing rate: $500 \mathrm{~mm} / \mathrm{s}^{2}$ \\
5 & 300 & $50 \rightarrow 80$ & 5 & 270 & 270 \\
\hline
\end{tabular}

*The contact pressure demonstrated in the testing matrix was obtained by a model which takes the deformation of the strip material into consideration when determining the interfacial contact area [35].

(a)

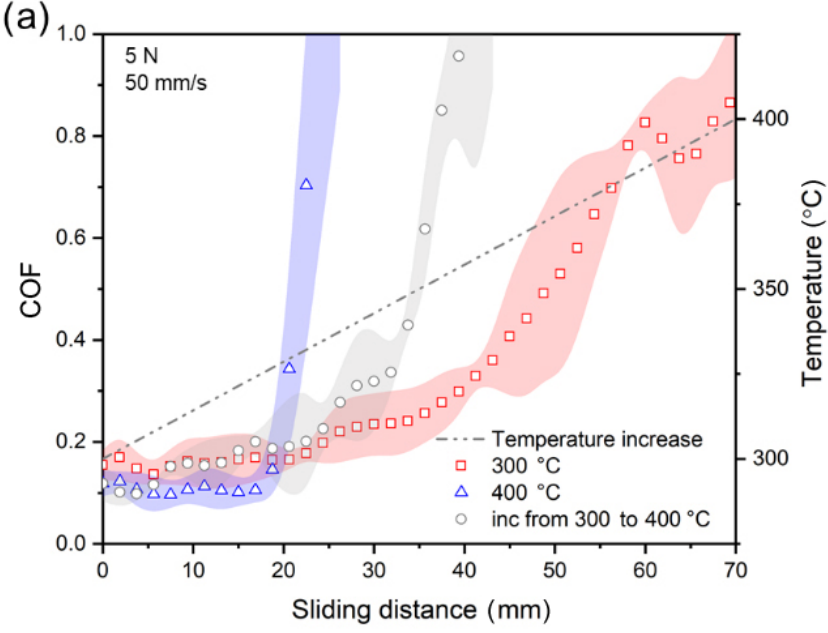

(b)

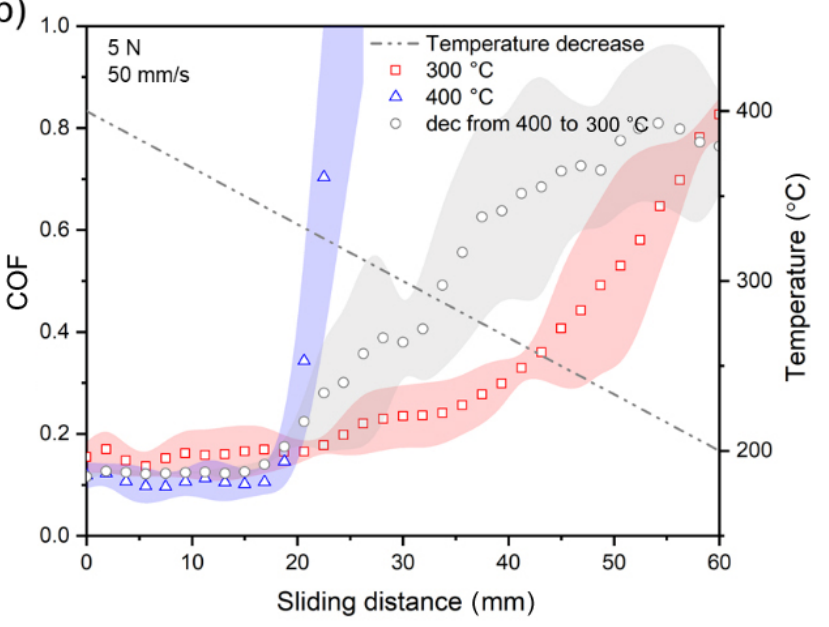

Fig. 2 Friction evolutions under constant temperature and complex loading conditions. Scatters represent the average friction values; envelope represents standard deviations; and line represents temperature evolution in the experiment. 
behaviour. A consistent trend can be observed from these tests where the COF commenced at a low value of $0.11-0.15$ and started to rapidly increase after sliding $10-30 \mathrm{~mm}$, indicating the phenomenon of premature breakdown.

Figure 2 shows the effects of temperature on the transient lubricant behaviours. The initial COF value decreased from 0.15 to 0.11 as the testing temperature increased from 300 to $400{ }^{\circ} \mathrm{C}$ under the constant temperature condition. When the testing temperature increased from 300 to $400{ }^{\circ} \mathrm{C}$, the viscosity of the entrapped lubricant decreased from 0.81 to $0.46 \mathrm{mPa} \cdot \mathrm{s}$ (determined by ASTM viscosity equations [36]); and thus, the shear stress of the boundary layers decreased. In addition, the plowing force decreased as the contacting material became softer. Therefore, the COF value at the initial stage decreased as the temperature increased.

The breakdown distance was observed as $17 \mathrm{~mm}$ at $400{ }^{\circ} \mathrm{C}$ indicated by a sharp increase of COF. However, the smooth ramp-up of the $\mathrm{COF}$ evolution at $300{ }^{\circ} \mathrm{C}$ made the clear identification of lubricant breakdown difficult. Hence, a proof increase by $10 \%$ of COF value at the initial stage was used as an indicator of the lubricant breakdown region. As such, the breakdown distance of the studied lubricant was identified as $25 \mathrm{~mm}$ when a constant temperature of $300{ }^{\circ} \mathrm{C}$ was applied. The decomposition of the lubricant liquid was accelerated as the temperature increased, which enhanced the diminution rate of the entrapped lubricant. In addition, the increasing temperature increased the wear rate of the coating film formed by the solid lubricant. Therefore, the consumption of the lubricant entrapped at the interface was accelerated as the temperature increased and the breakdown distance became shorter.

In the case of temperature increase from 300 to $400{ }^{\circ} \mathrm{C}$ at a changing rate of $1.4{ }^{\circ} \mathrm{C} / \mathrm{mm}, \mathrm{COF}$ evolution at the initial stage stabilized at 0.14 with a premature lubricant breakdown at $24 \mathrm{~mm}$. It was observed that the rising gradient at the temperature increase test was steeper than that at $300{ }^{\circ} \mathrm{C}$ but slower than $400{ }^{\circ} \mathrm{C}$. As temperature decreased from 400 to $300{ }^{\circ} \mathrm{C}$ at a changing rate of $-3.3{ }^{\circ} \mathrm{C} / \mathrm{mm}$, the $\mathrm{COF}$ values fluctuated at approximately 0.13 before the premature breakdown commenced at approximately $19 \mathrm{~mm}$. The gradient of COF with sliding distance reduced as the temperature was decreased until achieving a plateau.

Figure 3 shows the effects of contact load on the transient lubricant behaviours. The initial COF value was independent of the contact load between 5 and $10 \mathrm{~N}$. For the $5 \mathrm{~N}$ constant loading tests, at the initial stage, the COF value was approximately 0.15 and increased at an average rate of $0.017 \mathrm{~mm}^{-1}$ when the distance increased from 25 to $70 \mathrm{~mm}$. At the constant loading test of $10 \mathrm{~N}$, the COF values stabilized at 0.14 until reaching approximately $15 \mathrm{~mm}$ of sliding and increased at a rate of $0.03 \mathrm{~mm}^{-1}$ when the distance reached $43 \mathrm{~mm}$. The breakdown distance decreased from 25 to $15 \mathrm{~mm}$ as the constant load increased from 5 to $10 \mathrm{~N}$. (a)

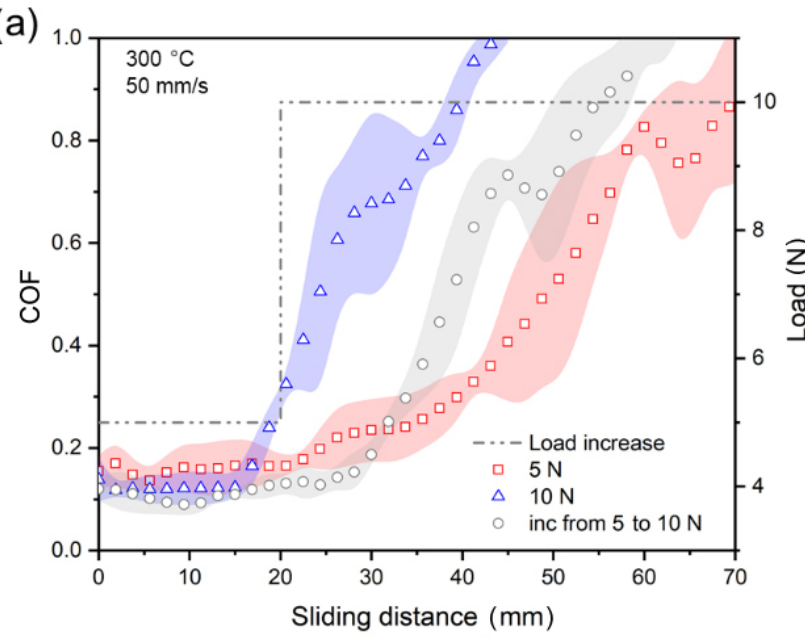

(b)

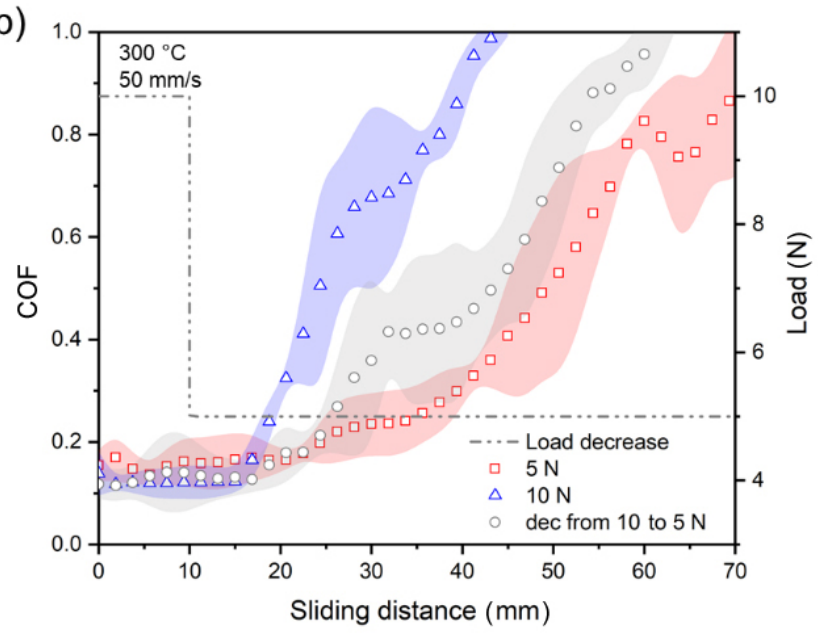

Fig. 3 Friction evolutions under constant load and complex loading conditions. Scatters represent the average friction values; envelope represents standard deviations; and line represents evolution of load in the experiment. 
According to the Stribeck curve and the Hersey number $(\eta N / \mathrm{P}$, where $\eta$ is the dynamic viscosity of the lubricant, $N$ is the speed, and $P$ is the contact load at the interface), friction at the boundary lubrication regime is a constant value which is not affected by the contact load, $P$ in Ref. [8]. The small difference between the friction values $(0.14$ and 0.15$)$ at the initial stage in the tests of 10 and $5 \mathrm{~N}$ may result from the solid lubricant particles suspended in the two-phase lubricant grease, which would cause larger fluctuations and deviations when compared to the situation where only the lubricant oil is involved.

As contact load increased, the lubricant film thickness would decrease, which is indicated by the Hersey number. Thus, more lubricant would be transferred onto the wear track or squeezed out from the interface, leading to a larger value of diminution rate of the entrapped lubricant amount and earlier lubricant breakdown. In addition, as demonstrated by the Holm-Archard's equation, the increasing contact load would result in higher wear rate, which means the coating film formed by the solid lubricant would be worn more quickly, and premature breakdown would occur.

As shown in Fig. 3(a), at a distance of $20 \mathrm{~mm}$, there was an abrupt increase of load (from 5 to $10 \mathrm{~N}$ ). The friction evolution demonstrated a breakdown distance of approximately $24 \mathrm{~mm}$ with an average friction value of 0.13 and a similar rising gradient of $0.027 \mathrm{~mm}^{-1}$ as that of the constant load test of $10 \mathrm{~N}$. In the test involving an abrupt load decrease (from 10 to $5 \mathrm{~N}$ ) at a distance of $10 \mathrm{~mm}$, the COF values stabilized at approximately 0.15 , began to increase at a distance of $19 \mathrm{~mm}$ and finally increased to 1 with a similar gradient of approximate $0.019 \mathrm{~mm}^{-1}$ as the $5 \mathrm{~N}$ test.

Figure 4 shows the effects of speed on the transient lubricant behaviours. The initial stage of friction evolution at $50 \mathrm{~mm} / \mathrm{s}$ exhibited a COF value of 0.15 and the breakdown distance of $30 \mathrm{~mm}$, while at $80 \mathrm{~mm} / \mathrm{s}$ it decreased to approximately $10 \mathrm{~mm}$ with the same COF value of 0.15 . According to the Stribeck curve and the Hersey number, COF value is independent of the sliding speed at the interface, and the lubricant film thickness would increase as the sliding speed increases, which reduces the amount of lubricant transferred onto the wear track and slows down the breakdown process. However, when the two-phase lubricant was applied, the wear rate of the coating film generated by the solid lubricant particles would increase as the sliding speed increased according to the Holm-Archard's equation, indicating the acceleration of lubricant breakdown at increasing speed. The combination of these two effects may finally give rise to a shorter breakdown distance at greater speeds.

When there was a steep acceleration of speed (from 50 to $80 \mathrm{~mm} / \mathrm{s}$ ) at a distance of $18 \mathrm{~mm}$, the COF stabilized at an average value of 0.15 before reaching $20 \mathrm{~mm}$ of sliding. As the sliding speed decreased (from 80 to $50 \mathrm{~mm} / \mathrm{s}$ ) at a distance of $10 \mathrm{~mm}$, the distance when premature breakdown commenced shared the same value of $10 \mathrm{~mm}$ as the result at $80 \mathrm{~mm} / \mathrm{s}$. However, the
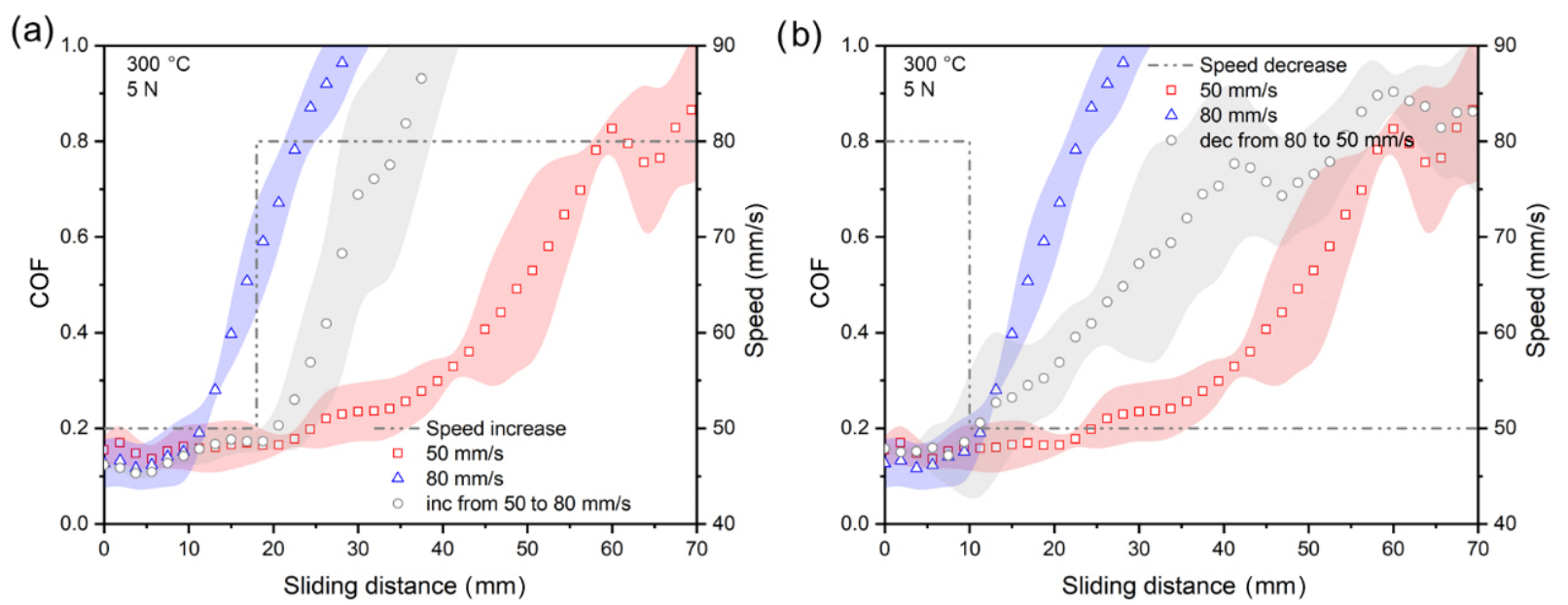

Fig. 4 Friction evolutions under constant speed and complex loading conditions. Scatters represent average friction values; envelope represents standard deviations; line represents evolution of speed in the experiment. 
effects of decreasing the sliding speed are demonstrated by the different gradients after the breakdown occurs. When the speed decreased to $50 \mathrm{~mm} / \mathrm{s}$ in the speed decrease test, the gradient $\left(0.017 \mathrm{~mm}^{-1}\right)$ reduced significantly compared to $80 \mathrm{~mm} / \mathrm{s}\left(0.041 \mathrm{~mm}^{-1}\right)$.

\subsection{Development of a visco-mechanochemical interactive friction model for the prediction of transient tribological behaviours of a two- phase lubricant}

The transient lubricant behaviours of the two-phase lubricant studied in the present research were caused by the changes in lubrication mechanisms during sliding wear, which transformed from fluid boundary lubrication to thin-film boundary lubrication and finally dry sliding (between substrate materials) [4, 10, 11, 37]. As such a visco-mechanochemical interactive friction model was developed considering the effects of both physical diminution and chemical decomposition on the evolutionary lubrication mechanisms enabling the predictions of the transient behaviours of the two-phase lubricant.

During the initial stage of sliding wear, the boundary lubrication was the dominant lubrication mechanism and friction force stemmed from the shearing force of the lubricant layers and the plowing force of the interacting asperities. As the siding distance increased, both physical diminution and chemical decomposition occurred. The physical diminution refers to lubricant thickness reduction due to the lubricant transfer (from the pin onto the wear track) and lubricant evaporation. As the friction tests in the present research were conducted at elevated temperatures of over $300{ }^{\circ} \mathrm{C}$ (flash point of OMEGA 35 is $196{ }^{\circ} \mathrm{C}$ ), in addition to the physical diminution, chemical decomposition of the two-phase lubricant would accelerate the lubricant thickness reduction resulting in the deposition of solid additive (graphite particles) on the substrate (pin) surface, which formed a thin layer of "graphite coating". This thin film was worn off easily during sliding wear which resulted in superior lubricity at elevated temperatures. During this process, the lubrication mechanism transformed from fluid boundary lubrication to thin-film boundary lubrication, followed by the breakdown of the thin film leading to the increase of COF and finally the dry sliding.
The COF increases from the value at the low friction stage to the final high value at the breakdown stage, demonstrating the transition of lubrication mechanisms from the boundary lubrication to the dry sliding condition. As the total lubricant thickness decreases, the fraction of the dry sliding region increases. Therefore, the complex nature of these transient behaviours and lubrication mechanisms of the tested two-phase lubricant was modelled by Eq. (1), in which friction originated from two distinct contact regions, specifically: from the lubricated region and the dry sliding region, respectively.

$$
\mu=(1-\beta) \mu_{1}(T)+\beta \mu_{\mathrm{d}}(T)
$$

where $\mu$ is the overall coefficient of friction; and the unlubricated area ratio (dry sliding area ratio), $\beta$, is introduced to model the residual lubricant volume entrapped at the contact interface. $(1-\beta) \mu_{1}$ is the friction attributed to the lubricated region and $\beta \mu_{\mathrm{d}}$ is the friction originating from the dry sliding region. As the thickness of the lubricant decreased, $\beta$ increased exponentially with the total lubricant thickness $h_{\mathrm{t}}$, as expressed by Eq. (2):

$$
\beta=\exp \left[-\left(h_{t} / \lambda_{1}\right)^{\lambda_{2}}\right]
$$

When $h_{\mathrm{t}}$ decreases to a critical value, which is determined by the average asperity heights, the premature breakdown commences, and the $\mathrm{COF}$ value begins to increase. $\lambda_{1}$ represents the surface roughness induced lubrication mechanism transition which is determined by the average height of asperities (and critical lubricant thickness) leading to premature breakdown, where a greater value of $\lambda_{1}$ represents a rougher tool surface. $\lambda_{2}$ determines the lubrication transition distance, where a lower value of $\lambda_{2}$ results in a larger transition distance from boundary lubrication to dry sliding, which can be found in lubricants with a high viscosity or large fraction of solid additives.

The total lubricant thickness $\left(h_{\mathrm{t}}\right)$ refers to the residual lubricant thickness on the pin surface, which is composed of the residual lubricant thickness of the two-phase liquid $\left(h_{1}\right)$, specifically OMEGA 35 , and the equivalent thickness of the thin layer or "graphite coating" $\left(h_{\mathrm{s}}\right)$, as expressed by Eq. (3). 


$$
h_{\mathrm{t}}(t)=h_{1}(t)+h_{\mathrm{s}}(t)
$$

As the lubricant was initially applied on the cold tool surfaces, $h_{\mathrm{s}}(0)=0$, and hence $h_{\mathrm{t}}(0)=h_{1}(0)$. As the sliding was initiated, $h_{1}$ began to decrease due to physical diminution and chemical decomposition. Meanwhile, the thin-film thickness $h_{\mathrm{s}}$ began to grow when evaporation and decomposition of the liquid lubricant occurred during high-temperature friction tests, i.e., the deposition of the solid additive (graphite) increased $h_{\mathrm{s}}$. Simultaneously, a competing wear process causing $h_{\mathrm{s}}$ reduction occurred when the sliding wear was initiated. The distinct mechanisms are modelled as follows.

\subsubsection{Transition of lubrication mechanism from fluid} boundary lubrication to thin-film boundary lubrication

The lubricant thickness reduction can be attributed to the combined effects of lubricant transfer, evaporation, and chemical decomposition, which is modelled by Eq. (4), where $h_{1}(t)$ is the thickness reduction rate of the two-phase lubricant.

$$
\begin{gathered}
h_{1}(t)=C\left[h_{1}(t)(P / \eta)^{k_{1}} v^{k_{2}}\right]+D(T)\left[h_{1}(t)\right]^{k_{\alpha}} \\
D(T)=D_{0} \exp \left(-Q_{\mathrm{D}} / R T\right)
\end{gathered}
$$

The first term of Eq. (4) refers to the physical diminution of the lubricant, which calculates the lubricant amount being physically transferred to the wear track, and is determined by the ratio of the contact pressure and viscosity [38, 39]; where $h_{1}(t)$ is the residual lubricant thickness of the two-phase liquid, $P$ is the mean interfacial pressure, $\eta$ is viscosity of the two-phase lubricant, $v$ is the relative sliding speed, and $C, k_{1}$, and $k_{2}$ are model parameters. The second term of Eq. (4) represents the thickness reduction due to evaporation and chemical decomposition of the lubricant, which is determined by the residual thickness of the lubricant. $D(T)$ represents a temperaturedependent vanishing (including evaporation and decomposition) coefficient for the liquid phase, calculated by the Arrhenius equation [40, 41], as expressed by Eq. (5). $k_{\alpha}$ is a model constant.

As shown in Fig. 5, the residual lubricant thickness $\left(h_{1}\right)$ decreases monotonously during the sliding process.

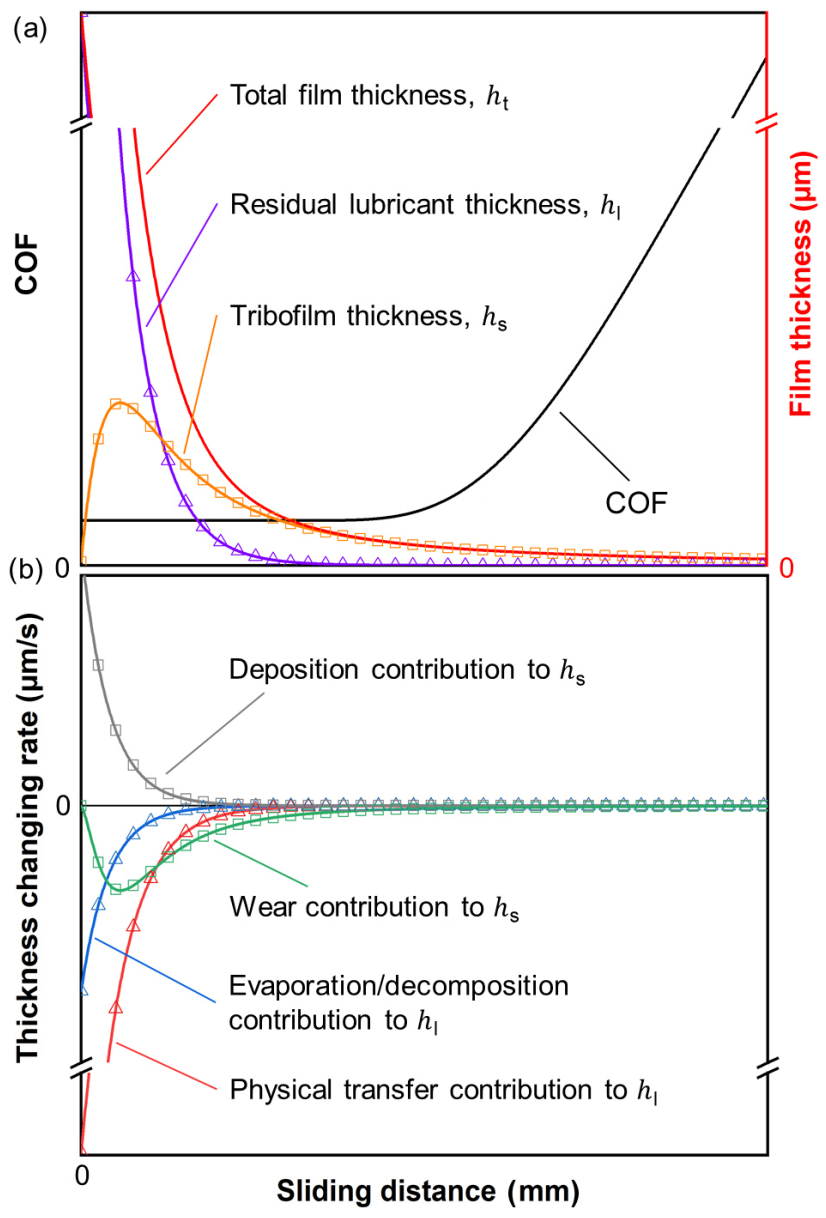

Fig. 5 Predicted lubricant response to high-temperature sliding wear: evolution of $\mathrm{COF}$, and the two-phase lubricant thickness and its changing rates.

According to Eq. (4), the reduction is due to two contributing factors: physical transfer and evaporation/ decomposition, which are demonstrated by curves of thickness changing rate (Fig. 5(b)).

\subsubsection{Transition of lubrication mechanism from thin-film boundary lubrication to dry sliding}

As the sliding process was conducted at elevated temperatures, the solid additive (graphite particles) was deposited on the substrate which formed a thin layer at the contact interface after the liquid phase vanished. As such, $h_{\mathrm{s}}$ increased due to solid deposition, while wear occurred the thin coating layer deposited by the solid additives was worn off during sliding which decreased the layer thickness $\left(h_{\mathrm{s}}\right)$. Thus, the contributions of the competing mechanisms on the changing rate of layer thickness, $h_{\mathrm{s}}(t)$, are expressed in Eq. (6): 


$$
\begin{gathered}
h_{\mathrm{s}}(t)=m D(T)\left[h_{1}(t)\right]^{\mathrm{k}_{\alpha}}-K(T) \frac{P^{n_{p}} \mathrm{v}^{\mathrm{n}_{\mathrm{v}}}}{H_{\mathrm{c}}} \\
K(T)=K_{0} \exp \left(-Q_{K} / R T\right) \\
H_{\mathrm{c}}=H_{\mathrm{s}} /\left[h_{\mathrm{s}}(t)\right]^{\mathrm{k}_{\mathrm{s}}}
\end{gathered}
$$

where $m$ is the equivalent volume fraction of solid additives in the lubricant which is assumed to be a constant. $n_{\mathrm{P}}$ and $n_{\mathrm{v}}$ are model constants. $K(T)$ is a temperature-dependent wear coefficient which is calculated by the Arrhenius equation, as expressed by Eq. (7). The first term of Eq. (6) refers to the deposition of thin film from solid additive due to the evaporation and decomposition of the lubricant. The second term represents the reduction of thin-film thickness due to abrasive wear, which is derived based on the Holm-Archard's equation describing the relationship between wear depth and contact conditions during sliding wear [42]. $H_{c}$ denotes the combined hardness of tribo-system, which is determined by the hardness of graphite layer $\left(H_{\mathrm{s}}\right)$ and the residual film thickness $\left(h_{\mathrm{s}}(t)\right)[43,44] . k_{\mathrm{s}}$ is a model constant.

Figure 5 demonstrates the schematic evolution of the total film thickness $\left(h_{\mathrm{t}}\right)$ and COF $h_{\mathrm{t}}$ decreased monotonously along the sliding process. As the critical film thickness was reached (when there is a $10 \%$ increase of value during the initial stage), the premature breakdown occurred. It is also observed that although $h_{\mathrm{s}}$ was less than $h_{l}$ at the initial stage of sliding, the decrease of $h_{\mathrm{s}}$ was slower than $h_{1}$ and, thus, $h_{\mathrm{s}}$ exceeded $h_{1}$ when the breakdown occurs, which reveals the phenomenon of dominant mechanism transformation from fluid boundary lubrication to thin-film boundary lubrication and finally dry sliding condition.

The first and second terms of Eq. (6) are demonstrated in Fig. 5(b) by the curves of deposition contribution and wear contribution to the changing rate of film thickness $\left(h_{\mathrm{s}}\right)$, respectively. After the lubricant was applied on the cold tool surfaces, the deposition contribution to the solid film peaks and wear rate was equivalent to zero as $h_{\mathrm{s}}(0)=0$ and $h_{\mathrm{s}}$ reached its maximum value, which means $h_{\mathrm{s}}$ increased at the beginning of forming. Deposition rate decreased and wear rate increased along the sliding, thus, $h_{s}$ began to decrease and became negative, at which point $h_{s}$ increased to its maximum value. Subsequently $h_{s}$ decreased to zero as the lubricant was completely removed from the interface. When $h_{\mathrm{s}}$ approaches 0 , the wear rate of film thickness $\left(h_{\mathrm{s}}\right)$ equals to 0, as expressed by Eqs. (6) and (8).

\subsubsection{Calibration of model parameters}

Calibration of parameters were conducted by the autonomous friction modelling program embedded in the tribo-mate system [33]. The calibration process is essentially an optimisation of an objective function which is usually determined by computing the deviations between the predicted results by the interactive model and the experimental results. By applying this objective function, the in-situ friction modelling program enables automated model calibration through an enhanced curve fitting module which allows the user to carry out manual pre-fitting and automatic fine-tuning of the model. After the data has been processed through the necessary modules, the interactive friction model is established, and optimised based on the experimental results. The initial thickness of the lubricant used in the model calibration was $50 \mu \mathrm{m}$, being consistent with the initial lubricant thickness applied in the friction tests. This was used as a case-study to demonstrate the predictive nature of this interactive friction model.

Model parameters after calibration and optimisation with the results at constant friction tests are demonstrated in Table 2. The testing results under complex loading conditions, including temperature, load, and speed changes, were then compared with the modelling results, and it was found that close agreements were achieved, with the deviations between the experimental and modelling results less than $10 \%$.

\subsection{Discussion}

\subsubsection{Effects of temperature on the transient tribological behaviours of the two-phase lubricant}

Figure 6 illustrates the evolution of COF and film thickness under constant temperature and temperature reduction conditions. Close agreements have been achieved between experimental and modelling results under both constant and complex loading conditions as shown in Fig. 6(a). 
Table 2 Lubricant and model parameters of the interactive friction model for OMEGA 35.

\begin{tabular}{|c|c|c|c|c|c|}
\hline$\lambda_{1}(\mu \mathrm{m})$ & $\lambda_{2}(-)$ & $k_{1}(-)$ & $k_{2}(-)$ & $k_{\alpha}(-)$ & $\eta(\mathrm{cSt})$ \\
\hline 0.28 & 2.21 & 1.25 & 2.59 & 1.17 & 35 \\
\hline$D_{0}\left(\mathrm{~s}^{-1}\right)$ & $Q_{\mathrm{D}}\left(\mathrm{kJ} \cdot \mathrm{mol}^{-1}\right)$ & \multicolumn{2}{|c|}{$c(\mathrm{~mm} /(\mathrm{GPa} \cdot \mathrm{s}))$} & $R(\mathrm{~J} /(\mathrm{K} \cdot \mathrm{mol}))$ & $m(-)$ \\
\hline $1.19 \mathrm{e}+5$ & 47.63 & \multicolumn{2}{|c|}{0.30} & 8.314 & 0.25 \\
\hline$K_{0}\left(\mathrm{~s}^{-1}\right)$ & $Q_{\mathrm{K}}\left(\mathrm{kJ} \cdot \mathrm{mol}^{-1}\right)$ & $n_{\mathrm{P}}(-)$ & $n_{\mathrm{v}}(-)$ & $H_{\mathrm{s}}(\mathrm{MPa})$ & $k_{\mathrm{s}}(-)$ \\
\hline $8.77 e+3$ & 70.48 & 1.09 & 2.83 & 88 & 1.78 \\
\hline
\end{tabular}

(a)

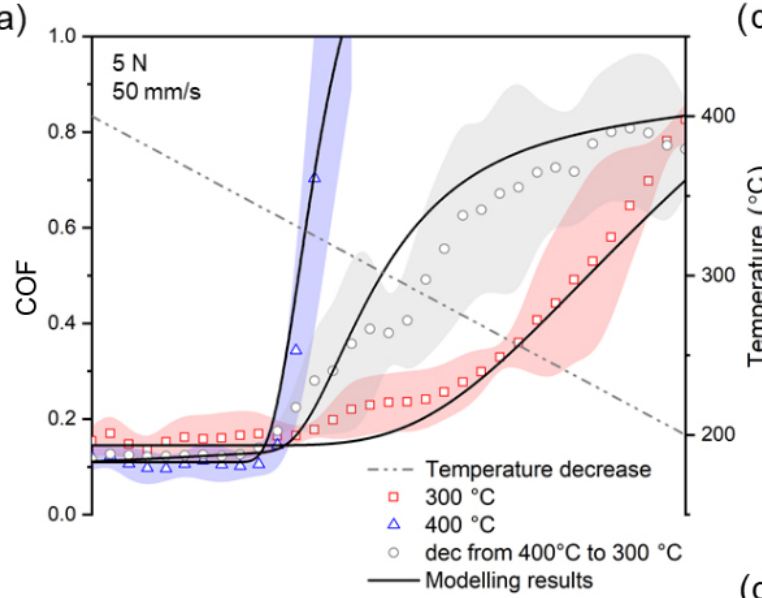

(b)

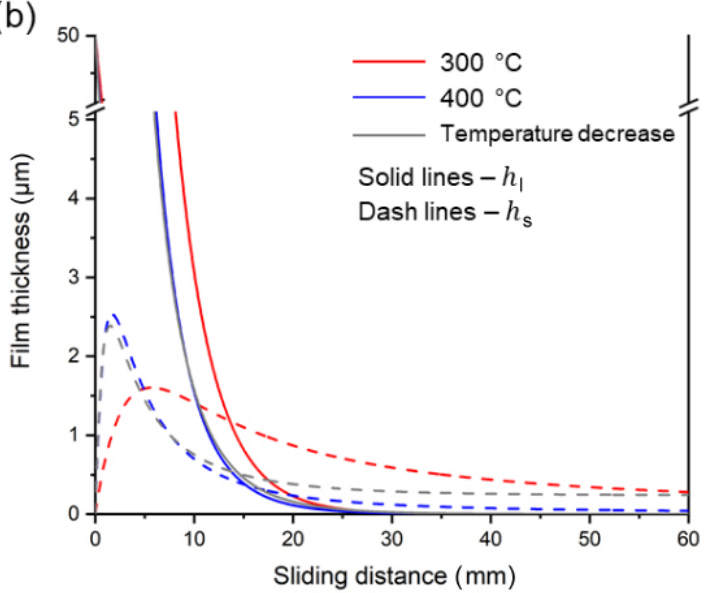

(c)

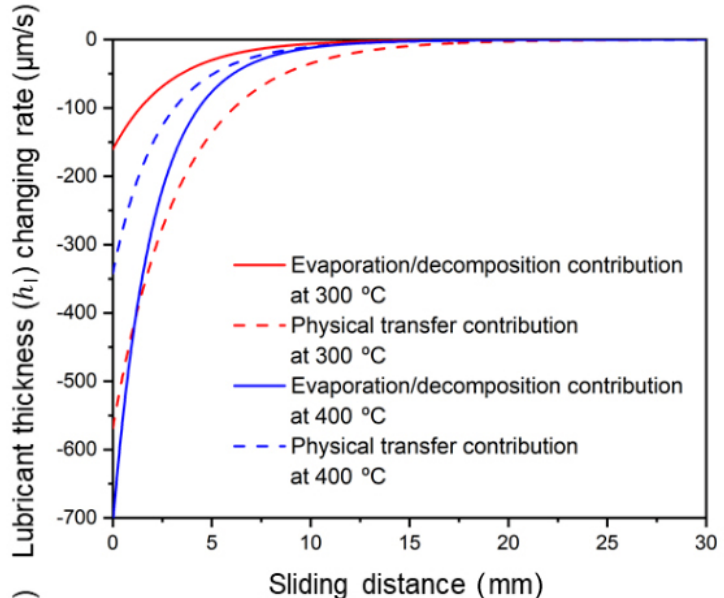

(d)

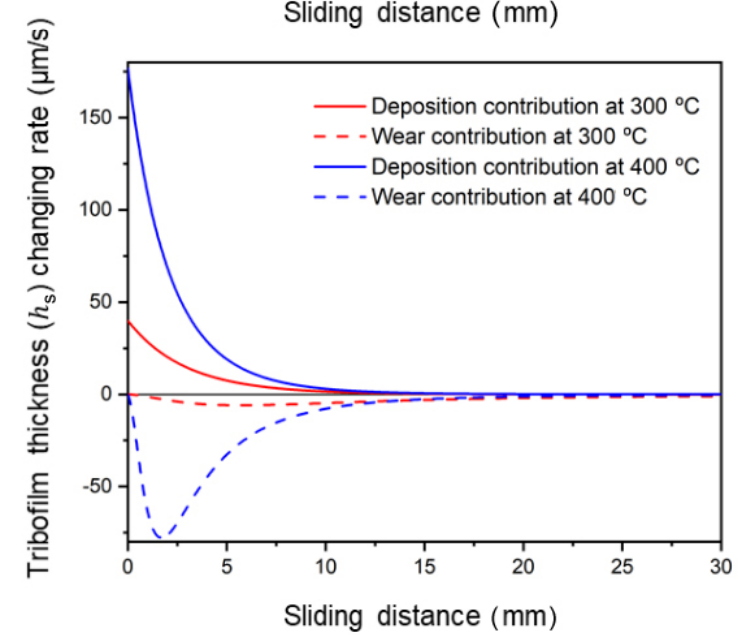

Fig. 6 Effects of temperature on the two-phase lubricant behaviours and transient tribological phenomena: evolutions of COF, lubricant thickness, and thickness changing rate.

As the temperature was increased from 300 to $400{ }^{\circ} \mathrm{C}$, evaporation and decomposition of the liquid phase were accelerated; and thus the contribution of evaporation and decomposition to the lubricant thickness $\left(h_{1}\right)$ reduction was enhanced from 160 to $709 \mu \mathrm{m} / \mathrm{s}$ at the beginning of sliding, as shown by the solid lines in Fig. 6(c). The total amount of thickness reduction due to evaporation/decomposition contribution during the whole sliding increased from 9.7 to $31.7 \mu \mathrm{m}$. Although a constant contact load was applied, the interfacial contact pressure was decreased from 270 to $180 \mathrm{MPa}$ due to softening of the workpiece material as temperature was increased from 300 to $400{ }^{\circ} \mathrm{C}$. This resulted in a reduction of lubricant transfer and thus a reduced contribution of thickness reduction by $54.6 \%$ due to physical transfer. As shown in Fig. 6(d), deposition of the solid additives due to evaporation and decomposition of the liquid phase was increased as temperature increased, which led to a rapid increase of thickness of the solid layer $\left(h_{\mathrm{s}}\right)$ 
and larger peak value at $400{ }^{\circ} \mathrm{C}$ at the initial stage, as shown in Fig. 6(b). However, the increased temperature and reduced combined hardness resulted in a larger wear rate. Therefore, after reaching the peak value, $h_{\mathrm{s}}$ decreases at a greater rate at $400{ }^{\circ} \mathrm{C}$, leading to a shorter breakdown distance from $26.8 \mathrm{~mm}$ at $300{ }^{\circ} \mathrm{C}$ to $16.4 \mathrm{~mm}$ at $400{ }^{\circ} \mathrm{C}$, as shown in Fig. 6(a).

It can be observed that, at elevated temperatures, the lubricant thickness, $h_{1}$, was much larger than the $h_{\mathrm{s}}$, at the initial stage of sliding, which indicates that the fluid boundary lubrication was dominant at this stage. As sliding proceeded, $h_{1}$ decreased faster due to both evaporation/decomposition and physical transfer and $h_{\mathrm{s}}$ exceeded $h_{1}$ before the lubricant breakdown occurred, as shown in Fig. 6(b), which indicated the transformation of dominant lubrication condition from fluid boundary lubrication to thin-film boundary lubrication. Finally, this was transformed to dry sliding condition as $h_{\mathrm{s}}$ decreased to 0 .

(a)

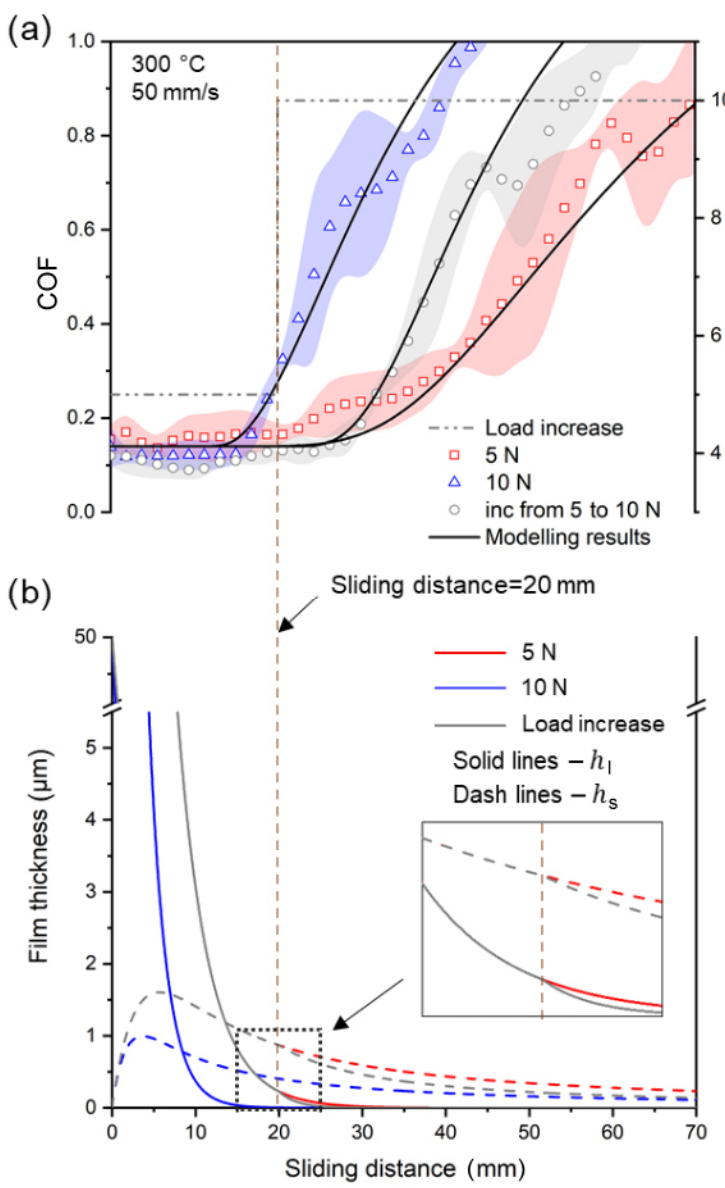

3.3.2 Effects of load on the transient tribological behaviours of the two-phase lubricant

Figure 7 demonstrates the evolutions of friction and film thickness under both constant contact load and abrupt load changing conditions. As the contact load increased, additional lubricant was transferred to the contacting counterpart or squeezed out from the interface, leading to a higher reduction rate of the lubricant liquid and thus less deposition of the solid additives on the substrate material. In addition, the wear rate of solid film was greater at higher contact load conditions. Therefore, earlier lubricant breakdown occurred at $10 \mathrm{~N}$ compared to $5 \mathrm{~N}$, as demonstrated by Fig. 7(a).

As load increased (from 5 to $10 \mathrm{~N}$ ), reduction of lubricant thickness $\left(h_{1}\right)$ due to physical transfer was accelerated from the beginning of sliding from 568 to $1,109 \mu \mathrm{m} / \mathrm{s}$, as shown in Fig. 7(c). As the lubricant thickness $\left(h_{1}\right)$ decreased faster at $10 \mathrm{~N}$, the mechanism

(c)

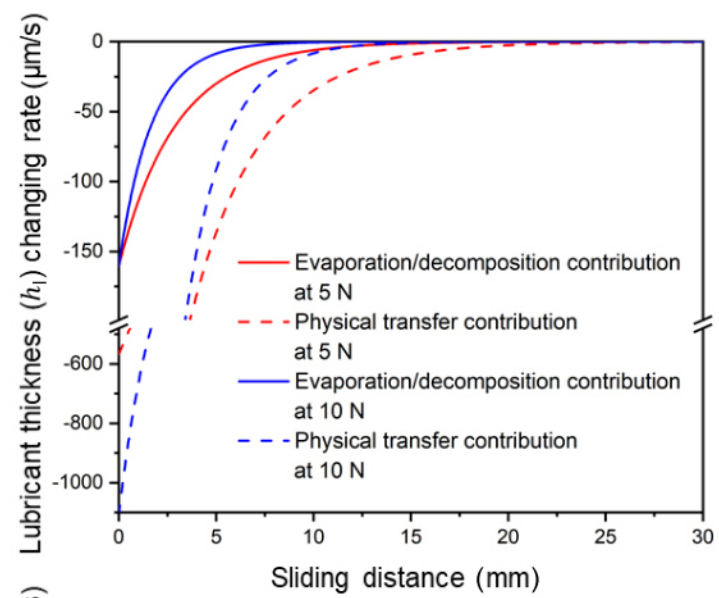

(d)

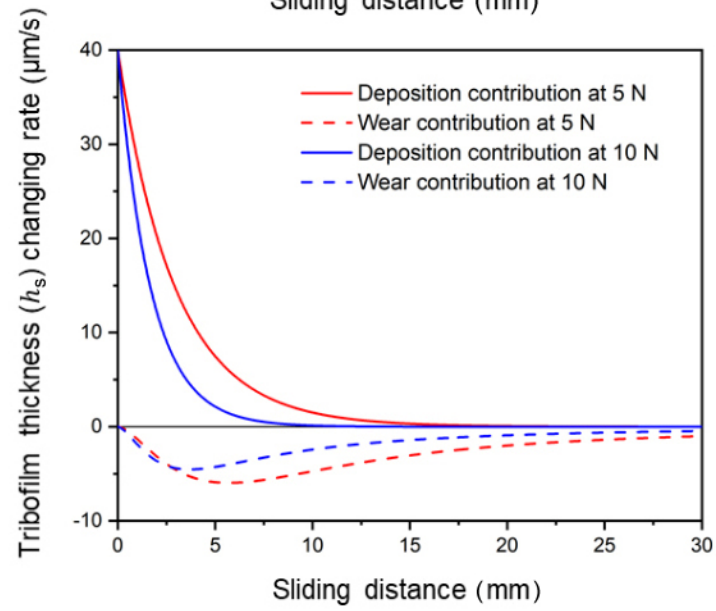

Fig. 7 Effects of load on the two-phase lubricant behaviours and transient tribological phenomena: evolutions of COF, lubricant thickness and thickness changing rate. 
transformation from fluid boundary lubrication to thin-film boundary lubrication was accelerated. Since both constant load tests at 5 and $10 \mathrm{~N}$ were conducted at the temperature of $300{ }^{\circ} \mathrm{C}$, the initial value of reduction due to evaporation and decomposition of liquid phase was the same followed by smaller reduction values at contact load of $10 \mathrm{~N}$ due to a faster reduction of $h_{1}$. Similar trends with the increase of $h_{\mathrm{s}}$ between 5 and $10 \mathrm{~N}$ were observed, as shown in Fig. 7(d), which caused $h_{\mathrm{s}}$ to increase at a greater rate and achieve a higher peak value at the contact load of $5 \mathrm{~N}$ compared to $10 \mathrm{~N}$ (Fig. 7(b)). As wear rate of the film increased due to increased load, the transition process from thin-film boundary lubricated condition to dry sliding was accelerated which led to a reduced breakdown distance from 26.8 to $14.2 \mathrm{~mm}$.

The developed interactive model is capable of predicting the transient lubricant behaviours under abrupt load changing conditions as shown by the close agreements between experimental and modelling results in Fig. 7(a). In the load increase test at a distance of $20 \mathrm{~mm}$, there was an abrupt change of contact load (from 5 to $10 \mathrm{~N}$ ). Film thickness evolutions at load increase condition overlapped with that at $5 \mathrm{~N}$ before the changing point. At the changing point, the reduction rate for the solid film suddenly increased from 1.93 to $3.51 \mu \mathrm{m} / \mathrm{s}$ and for the liquid lubricant from 2.88 to $5.34 \mu \mathrm{m} / \mathrm{s}$, leading to deviations of film thickness away from the constant loading curve and, thus, earlier breakdown occurred in the load increase test, as shown in Figs. 7(a) and 7(b). In addition, close values of the COF gradient after breakdown between the load increase test and the constant loading test of $10 \mathrm{~N}$ were accurately predicted and illustrated by the modelling results as $0.029 \mathrm{~mm}^{-1}$, which was consistent with the experimental observations.

\subsubsection{Effects of speed on the transient tribological behaviours of the two-phase lubricant}

Figure 8 demonstrates the effects of the sliding speed on the transient behaviours of the two-phase lubricant. As the sliding speed increased, additional lubricant
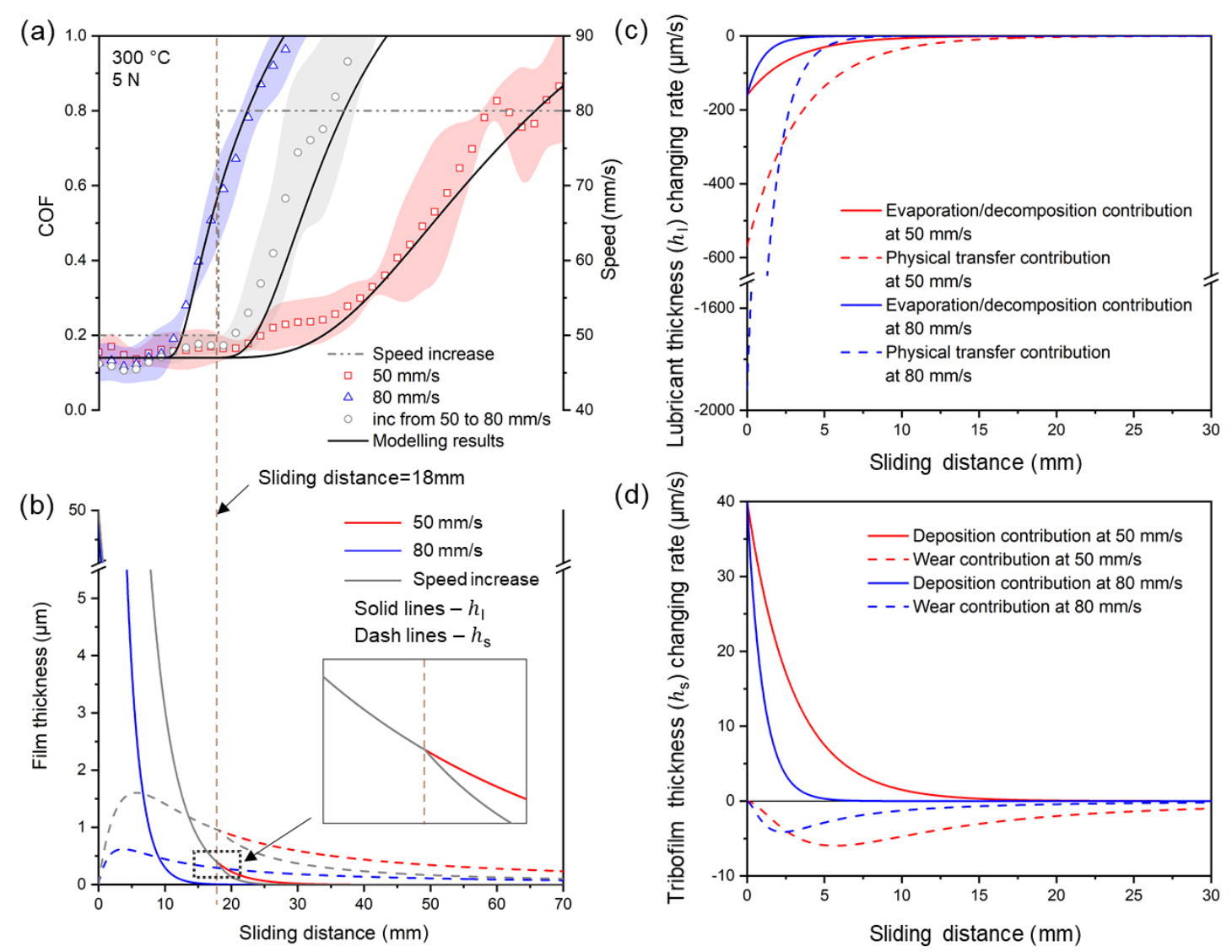

Fig. 8 Effects of speed on the two-phase lubricant behaviours and transient tribological phenomena: evolutions of COF, lubricant thickness, and thickness changing rate. 
diminished due to physical transfer (to the wear track) resulting in a greater thickness reduction of the lubricant $\left(h_{1}\right)$, as shown in Figs. 8(b) and 8(c), which resulted in an accelerated transition from fluid boundary lubrication to thin-film boundary lubrication. The exposure time of the lubricant at elevated temperatures was shortened and thus a lower amount of solid layer was deposited at the substrate material which was contributed from the liquid evaporation and decomposition, as shown in Fig. 8(d). Furthermore, wear rate of the solid film increased with increasing sliding speed, which resulted in a larger film thickness reduction rate and shorter transition distance from thin-film boundary lubrication to dry sliding, i.e., earlier lubricant breakdown.

In the speed increase test at a distance of $18 \mathrm{~mm}$, there was a steep acceleration of the sliding speed (from 50 to $80 \mathrm{~mm} / \mathrm{s}$ ), as shown in Fig. 6(a). After the speed change was implemented, the reduction of lubricant thickness $\left(h_{1}\right)$ was accelerated due to increased physical transfer. In addition, wear rate also increased with increasing speed. Therefore, both factors contributed to faster reduction of film thickness and shorter breakdown distance in the speed increase test, as shown in Figs. 8(a) and 8(b). It can be observed that the predicted increasing gradient of $0.039 \mathrm{~mm}^{-1}$ at the speed increase condition was the same as that of constant speed at $80 \mathrm{~mm} / \mathrm{s}$, which was close to the experimental results of $0.041 \mathrm{~mm}^{-1}$ at $80 \mathrm{~mm} / \mathrm{s}$ and speed increase conditions.

In general, the effects of contact conditions, e.g., temperature, load, and speed, and their abrupt changes on COF evolutions and the film thickness considering chemical decomposition and physical diminution can be accurately captured by the developed viscomechanochemical interactive friction model, and predictions of transient tribological behaviours of the two-phase lubricant can be made accordingly.

\section{Conclusions}

In the present study, the transient tribological behaviours of a two-phase lubricant were investigated under the complex loading conditions, including abrupt changes in load, speed, and temperature at the tool/workpiece interface. The friction tests were conducted utilizing the autonomous testing equipment, Tribo-mate, comprised of an operational robot and control software to enable accurate implementations of complex loading profiles. A novel visco-mechanochemical interactive friction model was developed considering the chemical decomposition and physical diminution effects as a function of instantaneous contact conditions. Close agreements were achieved between the testing and modelling results. The following conclusions can be drawn according to the investigations:

1) The transient tribological behaviours of the twophase lubricant are caused by the complex nature of the lubrication mechanisms present at the interface. During sliding, both physical diminution and chemical decomposition occurred leading to lubricant thickness reduction, which transformed the lubrication mechanism from fluid boundary lubrication to thinfilm boundary lubrication and finally dry sliding (between substrate materials);

2) The initial stage with low friction values was followed by a rapid increase of COF due to the chemical decomposition, and physical diminution effects of the entrapped lubricant and consequent breakdown phenomenon when the total thickness of the lubricant reduces to a critical value which is usually determined by the interfacial asperity heights;

3) The lubricant breakdown phenomenon and thickness changing processes are affected by the contact conditions at the interface and the sliding distance. The increase of temperature, pressure, and speed at the tool/workpiece interface would accelerate the consumption of lubricant during sliding and thus lead to premature lubricant failure and shorter breakdown distances;

4) The visco-mechanochemical interactive friction model describes the effects of temperature, pressure and speed on the transient lubricant behaviours and takes the evolution of two phases induced by physical diminution and chemical decomposition into consideration. The model is capable of capturing responses of film thickness and its changing rate due to abrupt changes in contact conditions and accurately predicting corresponding friction evolutions as a function of the complex loading conditions and the sliding distance. 


\section{Acknowledgements}

This study was supported by the China Scholarship Council (CSC) with Grant No. 201706230235. CSC is national institution that supports Chinese students to participate in overseas M.S. and Ph.D. programs. In addition, the strong support from the Institute of Automation, Heilongjiang Academy of Sciences, for this funded research is much appreciated.

Open Access This article is licensed under a Creative Commons Attribution 4.0 International License, which permits use, sharing, adaptation, distribution and reproduction in any medium or format, as long as you give appropriate credit to the original author(s) and the source, provide a link to the Creative Commons licence, and indicate if changes were made.

The images or other third party material in this article are included in the article's Creative Commons licence, unless indicated otherwise in a credit line to the material. If material is not included in the article's Creative Commons licence and your intended use is not permitted by statutory regulation or exceeds the permitted use, you will need to obtain permission directly from the copyright holder.

To view a copy of this licence, visit http://creativecommons.org/licenses/by/4.0/.

\section{References}

[1] Zhang J, Ewen J P, Ueda M, Wong J S S, Spikes H A. Mechanochemistry of zinc dialkyldithiophosphate on steel surfaces under elastohydrodynamic lubrication conditions. ACS Appl Mater Interfaces 12(5): 6662-6676 (2020)

[2] $\mathrm{Hu}$ Y, Zheng Y, Politis D J, Masen M A, Cui J, Wang L. Development of an interactive friction model to predict aluminum transfer in a pin-on-disc sliding system. Tribol Int 130: 216-228 (2019)

[3] Ma G J, Wang L L, Gao H X, Zhang J, Reddyhoff T. The friction coefficient evolution of a TiN coated contact during sliding wear. Appl Surf Sci 345: 109-115 (2015)

[4] Yang X, Liu X C, Liu H L, Politis D J, Leyvraz D, Wang L L. Experimental and modelling study of friction evolution and lubricant breakdown behaviour under varying contact conditions in warm aluminium forming processes. Tribol Int 158: 106934 (2021)

[5] Karbasian H, Tekkaya A E. A review on hot stamping. $J$ Mater Process Technol 210(15): 2103-2118 (2010)

[6] Wang Z, Dohda K, Haruyama Y. Effects of entraining velocity of lubricant and sliding velocity on friction behavior in stainless steel sheet rolling. Wear 260(3): 249-257 (2006)
[7] Pereira M P, Yan W Y, Rolfe B F. Sliding distance, contact pressure and wear in sheet metal stamping. Wear 268(11-12): 1275-1284 (2010)

[8] Bhushan B. Introduction to Tribology. UK: John Wiley \& Sons, Ltd., 2013.

[9] Bay N, Olsson D D, Andreasen J L. Lubricant test methods for sheet metal forming. Tribol Int 41(9-10): 844-853 (2008)

[10] Hu Y, Wang L, Politis D J, Masen M A. Development of an interactive friction model for the prediction of lubricant breakdown behaviour during sliding wear. Tribol Int 110: 370-377 (2017)

[11] Noder J, George R, Butcher C, Worswick M J. Friction characterization and application to warm forming of a high strength 7000-series aluminum sheet. J Mater Process Technol 293: 117066 (2021)

[12] Cui S G, Zhu H T, Wan S H, Tran B, Wang L, Tieu K. Investigation of different inorganic chemical compounds as hot metal forming lubricant by pin-on-disc and hot rolling. Tribol Int 125: 110-120 (2018)

[13] Xia W Z, Zhao J W, Wu H, Zhao X M, Zhang X M, Xu J Z, Jiao S H, Wang X G, Zhou C L, Jiang Z Y. Effects of oil-inwater based nanolubricant containing $\mathrm{TiO}_{2}$ nanoparticles in hot rolling of 304 stainless steel. J Mater Process Technol 262: 149-156 (2018)

[14] Liu Y, Zhu B, Wang K, Li S Q, Zhang Y S. Friction behaviors of 6061 aluminum alloy sheets in hot stamping under dry and lubricated conditions based on hot strip drawing test. Tribol Int 151: 106504 (2020)

[15] Dong Y C, Zheng K L, Fernandez J, Fuentes G, Li X Y, Dong $\mathrm{H}$ S. Tribology and hot forming performance of self-lubricious NC/NiBN and NC/WC: C hybrid composite coatings for hot forming Die. J Mater Process Technol 252: 183-190 (2018)

[16] Yang X, Zhang Q L, Zheng Y, Liu X C, Politis D, Fakir $\mathrm{O}$ E, Wang L L. Investigation of the friction coefficient evolution and lubricant breakdown behaviour of AA7075 aluminium alloy forming processes at elevated temperatures. Int J Extrem Manuf 3(2): 025002 (2021)

[17] Huang H D, Tu J P, Gan L P, Li C Z. An investigation on tribological properties of graphite nanosheets as oil additive. Wear 261(2): 140-144 (2006)

[18] Holinski R. Lubrication mechanism of solid lubricants in oils. S L E Trans 18(4): 263-269 (1975)

[19] Bartz W J. Some investigations on the influence of particle size on the lubricating effectiveness of molybdenum disulfide. S L E Trans 15(3): 207-215 (1972)

[20] Wu H X, Khan A M, Johnson B, Sasikumar K, Chung Y W, Wang Q J. Formation and nature of carbon-containing tribofilms. ACS Appl Mater Interfaces 11(17): 16139-16146 (2019)

[21] Seymour B, Fu W X, Wright R A E, Luo H M, Qu J, Dai S, Zhao B. Improved lubricating performance by combining oil-soluble hairy silica nanoparticles and an ionic liquid as an additive for a synthetic base oil. ACS Appl Mater Interfaces 10(17): 15129-15139 (2018) 
[22] Li X W, Zhang D K, Xu X W, Lee K R. Tailoring the nanostructure of graphene as an oil-based additive: Toward synergistic lubrication with an amorphous carbon film. ACS Appl Mater Interfaces 12(38): 43320-43330 (2020)

[23] Chouhan A, Kumari S, Sarkar T K, Rawat S S, Khatri O P. Graphene-based aqueous lubricants: Dispersion stability to the enhancement of tribological properties. ACS Appl Mater Interfaces 12(46): 51785-51796 (2020)

[24] Yousif A E, Nacy S M. Hydrodynamic behaviour of twophase (liquid-solid) lubricants. Wear 66(2): 223-240 (1981)

[25] Feng N S, Hahn E J. Density and viscosity models for two-phase homogeneous hydrodynamic damper fluids. $S L$ E Trans 29(3): 361-369 (1986)

[26] Alberts M, Kalaitzidou K, Melkote S. An investigation of graphite nanoplatelets as lubricant in grinding. Int $J$ Mach Tools Manuf 49(12-13): 966-970 (2009)

[27] Vazirisereshk M R, Martini A, Strubbe D A, Baykara M Z. Solid lubrication with $\mathrm{MoS}_{2}$ : A review. Lubricants 7(7): 57 (2019)

[28] Sliney H E. Solid lubricant materials for high temperaturesA review. Tribol Int 15(5): 303-315 (1982)

[29] Hol J, Meinders V T, de Rooij M B, van den Boogaard A H. Multi-scale friction modeling for sheet metal forming: The boundary lubrication regime. Tribol Int 81: 112-128 (2015)

[30] Hol J, Meinders V T, Geijselaers H J M, van den Boogaard A H. Multi-scale friction modeling for sheet metal forming: The mixed lubrication regime. Tribol Int 85: 10-25 (2015)

[31] Shisode M, Hazrati J, Mishra T, de Rooij M, van den Boogaard T. Mixed lubrication friction model including surface texture effects for sheet metal forming. J Mater Process Technol 291: 117035 (2021)

[32] Shisode M, Hazrati J, Mishra T, de Rooij M, Horn C T, van Beeck J, van den Boogaard T. Modeling boundary friction of coated sheets in sheet metal forming. Tribol Int 153: 106554 (2021)

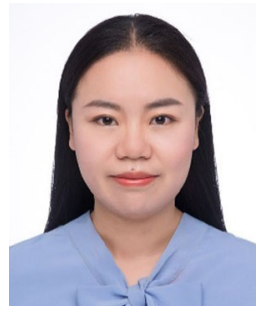

Xiao YANG. She is a Ph.D. candidate in the Department of Mechanical Engineering at Imperial College London, UK. She received her M.S. degree in the Institute of Forming

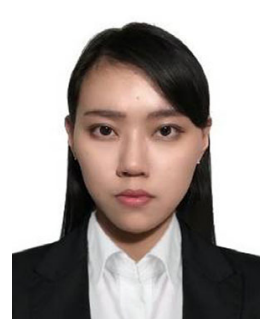

Lemeng ZHANG. She is studying for a M.S. degree in mechanical engineering at Imperial College London, UK. She obtained her B.S. degree in 2020 from University
[33] Yang X. Lubricant 4.0: Digitally enhanced lubricant development for metal forming applications. Ph.D. Thesis. London (UK): Imperial College London, 2021.

[34] Dohda K, Boher C, Rezai-Aria F, Mahayotsanun N. Tribology in metal forming at elevated temperatures. Friction 3(1): 1-27 (2015)

[35] Wang L, He Y, Zhou J, Duszczyk J. Modelling of plowing and shear friction coefficients during high-temperature ballon-disc tests. Tribol Int 42(1): 15-22 (2009)

[36] Seeton C J. Viscosity-temperature correlation for liquids. In Proceedings of the International Joint Tribology Conference, San Antonio, USA, 2006: 131-142.

[37] Liu X C, Yang X, Sun Y H, Politis D J, Mori K I, Wang L L. Characterization of thermomechanical boundary conditions of a martensitic steel for a FAST forming process. J Manuf Mater Process 4(2): 57 (2020)

[38] Begelinger A, Gee A W J D. Failure of thin film lubrication-A detailed study of the lubricant film breakdown mechanism. Wear 77(1): 57-63 (1982)

[39] Dowson D, Whomes T L. Paper 8: Side-leakage factors for a rigid cylinder lubricated by an isoviscous fluid. Proc Inst Mech Eng Conf Proc. London: SAGE Publications Sage, 1966: 165-176.

[40] Carey F A, Sundberg R J. Advanced Organic ChemistryPart A: Structure and Mechanisms. Springer Science \& Business Media, 2007.

[41] Connors K A. Chemical Kinetics: the Study of Reaction Rates in Solution. New York (USA): Wiley-VCH Verlag GmbH; 1990.

[42] Archard J F. Contact and rubbing of flat surfaces. J Appl Phys 24(8): 981-988 (1953)

[43] Korsunsky A M, McGurk M R, Bull S J, Page T F. On the hardness of coated systems. Surf Coat Technol 99(1-2): 171-183 (1998)

[44] Komvopoulos K. Sliding friction mechanisms of boundarylubricated layered surfaces: Part II-theoretical analysis. Tribol Trans 34(2): 281-291 (1991)

Technology and Equipment, Shanghai Jiao Tong University, China, in 2017. Her current research focuses on friction characterisation and interfacial behaviours in hot/warm metal forming processes.

College London, UK. Her current research focuses on the development of an autonomous laboratory system to study the friction and lubricant breakdown during hot metal forming. 


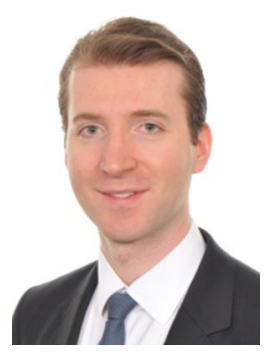

Denis J. POLITIS. He is a lecturer and head of the Manufacturing and Materials Modelling laboratory in the Department of Mechanical and Manufacturing Engineering at the University of Cyprus. He has more

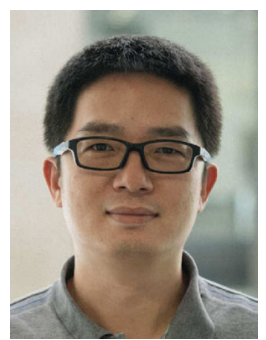

Jie ZHANG. He received his M.S. degree in tribology and surface engineering from thr China University of Geosciences (Beijing) in 2007. He subsequently joined the Tribology Group in Imperial College London as a Ph.D. student and completed

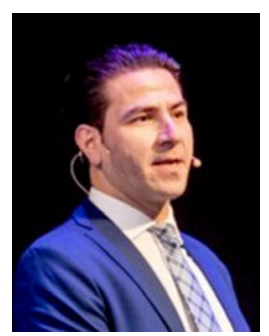

Mohammad M. GHARBI. He is an Europe, Middle East, Africa (EMEA) business development manager for the Hot and Warm Forming/Forging Technologies at

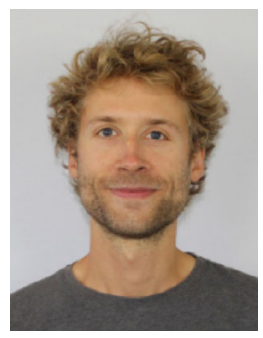

David LEYVRAZ. He is a R\&D Metallurgy Scientist at Novelis. His expertise is mainly on the high-strength aluminium alloy

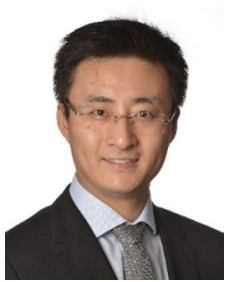

Liliang WANG. He is the head of Metal Forming and Modelling Group at Imperial College London. His major research interests include the design and development of advanced metal than 10 years research experience in sheet metal forming and forging technologies. He has worked on numerous research projects in collaboration with industrial companies that have been sponsored by European FP7 and H2020 grants.

in 2011. Since 2013 he started to work in the same group as a research associate on different projects. His main research areas cover boundary lubrication, wear, lubricant additives, elasto-hydrodynamic lubrication (EHD), micro-electro-mechanical system (MEMS), zinc dialkyldithiophosphate (ZDDP), mechanochemistry, and atmospheric Tribology.

Quaker Houghton. He has broad technical expertise from managing operations to negotiating complex transformation projects across all forming technologies, hot forming and forging lubricants market in Europe, Russia, North America, and Asia.

development for automotive applications, both on the production process (rolling, forming) and the in-service properties (crash).

forming technologies and manufacturing system. His work has made fundamental contributions to the characterization and modelling of materials and interfacial behaviours of engineering materials. 